\title{
Première fois
}

\section{Georges Bernard}

\section{Q OpenEdition}

\section{Journals}

Édition électronique

URL : http://journals.openedition.org/ccs/415

DOI : $10.4000 /$ ccs. 415

ISSN : 2558-782X

\section{Éditeur :}

Presses universitaires de Rennes, Association des lecteurs de Claude Simon

\section{Édition imprimée}

Date de publication : 8 juillet 2016

Pagination : 293-295

ISBN : 978-2-7535-4876-3

ISSN : 1774-9425

\section{Référence électronique}

Georges Bernard, «Première fois », Cahiers Claude Simon [En ligne], 11 | 2016, mis en ligne le 15 septembre 2017, consulté le 14 septembre 2020. URL : http://journals.openedition.org/ccs/415 


\title{
PREMIÈRE FOIS
}

\author{
Georges BERNARD
}

1982. J'ouvre Les Géorgiques. Entrer dans un livre est toujours une aventure. Il faut repérer les éléments qui feront la trame du récit, se plier à la logique du narrateur, découvrir page après page l'ébauche, puis la construction progressive d'une intrigue, se familiariser avec une écriture. Or, surprise! Rien de tout cela dans le geste que j'accomplis ce jour-là. Sans doute parce que je choisis une page au hasard. Il est question de militaires soumis à d'incompréhensibles manœuvres dans un paysage glacial et désolé. Une sensation de froid m'envahit subitement, physiquement, sans que je fasse le moindre effort. Je suis " dans » le récit. Je poursuis ma lecture. Les sensations se bousculent, me submergent. Je ressens dans ma chair ce "froid d'acier ", cette "sensation de solitude et de dispersion ", j'entends " le crissement de la neige sous les sabots », je vois "ces jardinets aux légumes gelés, flétris » avec "ces feuilles flasques, pendantes sous leur chapeau de neige ». Je lis dix, vingt, trente pages sans me rendre compte du temps qui passe, sans me soucier même de la suite du récit. Tout est dans l'immédiateté de l'écriture.

À ce stade, je ne connais rien du projet de l'auteur. Mais je sais déjà que je possède l'ingrédient le plus précieux pour poursuivre, pour comprendre: l'enthousiasme... Aidé par ma passion pour l'Histoire, je découvre ces trois destins confrontés à trois périodes tragiques: la Révolution Française, la guerre d'Espagne, la guerre de 39/40. Je suis fasciné par l'acuité du regard qui capte le plus infime détail, qui rompt constamment la linéarité du récit pour faire surgir l'insolite, l'inattendu, et qui, en cela, me restitue une vision du monde infiniment plus authentique dans sa subjectivité, que les intrigues les mieux ficelées du roman traditionnel. Fasciné également par l'art d'in- 
sérer ce foisonnement de sensations dans la grande aventure de l'Histoire. Et le livre prend forme peu à peu. Il se connecte avec mes propres souvenirs, il ouvre mille sentiers dans mon imaginaire, et je me rends compte que ce ravissement n'est autre qu'une révélation sur moi-même.

Plus rien ne m'arrêtera désormais dans ma passion de découvrir l'ensemble de l'œuvre. La Route des Flandres, L'Herbe, Le Vent, Histoire, lus en désordre, parfois simultanément avec la même ferveur, toujours fasciné par la "présence " des situations, l'ampleur des métaphores, la sensualité de l'écriture.

Un premier obstacle surgit lorsque j'aborde La Bataille de Pharsale. L'écriture splendide est toujours là (ah! cette errance dans ces paysages poussiéreux et calcinés des Balkans à la recherche du champ de bataille) mais il me faudra plus de temps pour assembler les pièces du puzzle sans être certain d'y parvenir (mais cela n'est-il pas mieux ainsi? Un livre de Claude Simon n'est-il pas toujours un espace ouvert sur différentes interprétations?)

Nouvelle expérience avec Triptyque. Surprise un peu contrariante: les premières pages me résistent. Où veut-il en venir? Vais-je renoncer? Non! Je recommence et bientôt quelques images surgissent. Je connais bien ces paysages du Jura qui furent ceux de mes vacances d'enfant. J'ai vu ces papillons blancs se poser sur des ombelles, j'ai vu ce jeune charretier " piquer de son ardillon la croupe d'une vache attardée qui prend un trot maladroit " et dont on voit « les pis roses balloter lourdement comme des cloches " Les réminiscences se succèdent, s'accumulent. Me voilà à nouveau captif de cette écriture. L'ouvrage prend forme. Je vois se dessiner ce récit au présent, cette pure description de trois séquences entrecroisées, ces incessants glissements d'une réalité factuelle à des représentations picturales, photographiques ou cinématographiques. Des morceaux d'anthologie: le cortège nuptial stoppé devant le passage à niveau, la violence des pulsions érotiques dans la pénombre de la grange ou sous la morne pluie des Flandres, la recherche angoissée de la fillette disparue, avec ce chant des criquets dans " la paisible nuit d'août ", "l'immensité de la vaste nuit soudain plus vaste encore ». Un chef-d'œuvre que l'on évitera toutefois de recommander à qui abordera l'œuvre de Claude Simon pour la première fois. Encore que...

Après Triptyque, j'ai les clés pour aborder Les Corps conducteurs, cette traversée de la cacophonie d'une grande métropole par un homme malade en contrepoint d'un survol aérien qui crée la distance et ramène cette agitation à un mouvement brownien d'insectes. Reste les livres de la dernière période, lus 
au fur et à mesure de leur sortie. L'Invitation, lecture accompagnée d'irrésistibles fous rires, L'Acacia avec de nouveaux morceaux d'anthologie (l'errance de la veuve, des tantes et de l'enfant à la recherche de la tombe du père, le départ du train en gare de Perpignan, l'évocation du voyage en Russie, la réadaptation après le retour de captivité etc.), Le Jardin des Plantes et le merveilleux Tramway, le Combray de Claude Simon.

Claude Simon est avec Proust le seul écrivain dont j'ai lu l'œuvre intégrale sans jamais éprouver la moindre déception, bien que je ne nie pas certaines difficultés d'approche qui concernent plus le lecteur que l'auteur. C'est pourquoi je ne cesse de m'étonner et parfois de m'indigner de la frilosité de la «critique officielle » face à cet immense écrivain. Comment secouer cette torpeur qui mêle l'ignorance à la mauvaise foi? Question qui n'en finira pas de se poser jusqu'à ce que la postérité le mette à sa juste place parmi les trois ou quatre plus grands romanciers français $\mathrm{du} \mathrm{xx}^{\mathrm{e}}$ siècle. 